\title{
Electrophoretic characterization of proteins in the plasma membrane of porcine spermatozoa
}

\author{
K. L. Esbenshade and E. D. Clegg \\ Department of Animal Sciences, Purdue University, West Lafayette, Indiana 47907, U.S.A.
}

Using immunological and cytochemical methods, several investigators have demonstrated that components on the surface of spermatozoa are altered during exposure of the spermatozoa to the female reproductive tract (Johnson \& Hunter, 1972; Aonuma et al., 1973; Oliphant \& Brackett, 1973). Recent evidence indicates that capacitation may also involve subtle modifications in the chemical composition of sperm membranes (Snider \& Clegg, 1975). The plasma membrane of porcine spermatozoa is being characterized in our laboratory to provide a foundation for subsequent studies of chemical changes during capacitation. In this paper, electrophoretic separation and partial characterization of proteins from plasma membrane of porcine spermatozoa is reported.

Plasma membrane was isolated from porcine spermatozoa by the procedure of Lunstra, Clegg \& Morré (1974). Briefly, sperm-rich semen was filtered at the time of collection through Miracloth (Chicopee Mills, Inc., New York, N.Y.) and then filtered through glass wool moistened with Ca-free Ringer solution. After low-speed centrifugation, spermatozoa were resuspended in Ringer-EDTA. The sperm suspension was cooled and sonicated under conditions that removed plasma membrane from the acrosomal region of the sperm head, but minimized disruption of other sperm membranes. After centrifugation at $6000 \mathrm{~g}$ for $10 \mathrm{~min}$ the plasma membrane-rich supernatant was bottomloaded in a discontinuous sucrose gradient (sucrose solutions with $d_{20}=1 \cdot 14,1 \cdot 17$ and 1.22) and centrifuged at $100,000 \mathrm{~g}$ for $90 \mathrm{~min}$. Plasma membrane was recovered from the $d=1 \cdot 14 / 1 \cdot 17$ interface, diluted with $1 \mathrm{~mm}$-sodium bicarbonate and centrifuged to sediment the membrane vesicles.

The purity of plasma membrane isolated by this procedure has been assessed by quantitative morphometry (Lembi, Morré, St-Thomson \& Hertel, 1971). After embedding for electron microscopy, thin sections were de-stained with periodic acid and then stained with acidic phosphotungstic acid (Morré, Clegg, Lunstra \& Mollenhauer, 1974). Under those conditions, the plasma membrane was the only membrane of porcine spermatozoa that was stained. Our preparations routinely contained $75-80 \%$ plasma membrane, with outer acrosomal membrane being the major contaminant. Other studies in this laboratory (unpublished data) show that the electrophoretic pattern of the proteins from purified outer acrosomal membrane is quite different from that of proteins from purified plasma membrane, indicating that the amount of outer acrosomal membrane in the preparations did not substantially alter the separation pattern.

Since some acrosomes were ruptured by the mild sonication of spermatozoa during plasma membrane isolation, it was possible that proteolytic activity could act on proteins of the plasma membrane. If that occurred, proteins extracted from the plasma membrane would include peptides that could appear as additional bands in electrophoresis. To minimize proteolytic activity, samples were cooled to 0 to $5^{\circ} \mathrm{C}$ before sonication and maintained at that temperature. Also, the $\mathrm{pH}$ of the preparation was kept at approximately $5 \cdot 5$. The specific activity of porcine acrosin, which is maximal at pH 8.5 (Polakoski, McRorie \& Williams, 1973), is low at pH 5.5. When photographic emulsion plates were used to detect proteolytic activity (Penn, Gledhill \& Darżynkiewicz, 1972) during the isolation procedure, no dispersion of the silver granules was observed.

Protein determinations were performed by the method of Lowry, Rosebrough, Farr \& Randall (1951).

Two systems of polyacrylamide gel electrophoresis (PAGE) were used to separate plasma membrane proteins. To obtain estimates of the molecular weights of protein bands, proteins were solubilized with sodium dodecyl sulphate (SDS) and urea at neutral pH and separated on SDSPAGE gels ( $8 \%$ acrylamide) as described by Zahler (1975). Purified protein standards of known 
molecular weight were subjected to electrophoresis under identical conditions and a quadratic equation was calculated by the least squares method to express molecular weight as a function of relative mobility in the gel. Relative mobility is the migration of a protein in the gel expressed as a fraction of the distance travelled by the tracking dye bromophenol blue (Weber \& Osborn, 1969). The standard proteins used in these experiments were fibrinogen, $\gamma$-globulin, bovine serum albumin, ovalbumin, $\alpha$-chymotrypsinogen, myoglobin and cytochrome c (Sigma Chemical Co., St Louis MO). Molecular weights of plasma membrane protein bands were estimated from their respective relative mobilities.

In addition to SDS-PAGE, plasma membrane proteins were separated on $7.5 \%$ acrylamide gels in an acidic system using phenol, urea and acetic acid to solubilize the membrane proteins (Zahler, 1975).

Proteins in the SDS-PAGE gels were stained by a procedure that simultaneously removed the SDS from the gels. The gels were placed in test tubes and treated at room temperature as follows: washed in $25 \%$ isopropyl alcohol and $10 \%$ trichloroacetic acid in water overnight; stained with $0.25 \%$ Coomassie Blue in $25 \%$ aqueous isopropyl alcohol containing $10 \%$ acetic acid for $6 \mathrm{hr}$; de-stained by washing in $10 \%$ isopropyl alcohol and $10 \%$ acetic acid in water for $1 \mathrm{hr}$; and de-stained electrophoretically for $1 \mathrm{hr}$ with methanol:acetic acid:water $(2: 3: 35$, by vol.). Glycoproteins were stained with periodic acid-Schiff (PAS) reagent by the procedure of Fairbanks, Steck \& Wallach (1971). Proteins in gels from the acidic system were stained with $0.25 \%$ Coomassie Blue in $7 \%$ acetic acid and de-stained with $7 \%$ acetic acid.

The standard curve calculated from SDS-PAGE to express the relationship between molecular weight and relative mobility was:

$$
\mathrm{Y}=1 \cdot 851 \mathrm{X}^{2}-3.092 \mathrm{X}+5 \cdot 447
$$

where $Y$ represents the $\log _{10}$ of molecular weight and $X$ represents relative mobility. The coefficient of correlation for that equation was 0.9992. Although a straight line is used normally to express the relationship between the logarithm of the molecular weight and relative mobility (Weber \& Osborn, 1969), more information could be obtained in this study if the relationship was expressed as a quadratic curve. With $8 \%$ acrylamide gels, most proteins with molecular weights up to about 200,000 follow a straight-line relationship. Proteins with molecular weights between 200,000 and 300,000 can enter the gels and migrate shorter distances, but the linear relationship between the logarithm of the molecular weight and relative mobility does not remain valid. With a quadratic curve, the molecular weight range could be extended to include proteins with molecular weights between 200,000 and 300,000 .

Table 1. Relative mobilities and molecular weights of the prominent proteins in plasma membrane of porcine spermatozoa separated by sodium dodecyl sulphatepolyacrylamide gel electrophoresis

\begin{tabular}{ccc}
\hline $\begin{array}{c}\text { Proteins as } \\
\text { migrated } \\
\text { from origin }\end{array}$ & Relative mobilities* & Molecular weight \\
\hline 1 & $0.010 \pm 0.001$ & $260,000 \dagger$ \\
2 & $0.026 \pm 0.001$ & $230,000 \dagger$ \\
3 & $0.056 \pm 0.002$ & $190,000 \dagger$ \\
4 & $0.088 \pm 0.004$ & 155,000 \\
5 & $0.090 \pm 0.007$ & 150,000 \\
6 & $0.104 \pm 0.005$ & $140,000 \dagger$ \\
7 & $0.153 \pm 0.006$ & 100,000 \\
8 & $0.236 \pm 0.011$ & 66,000 \\
9 & $0.327 \pm 0.012$ & 43,000 \\
10 & $0.507 \pm 0.021$ & $22,500 \dagger$ \\
11 & $0.760 \pm 0.014$ & $14,500 \dagger$ \\
\hline
\end{tabular}

* Values represent means for 5 replicates \pm S.E.M.

$\uparrow$ Carbohydrate-positive. 


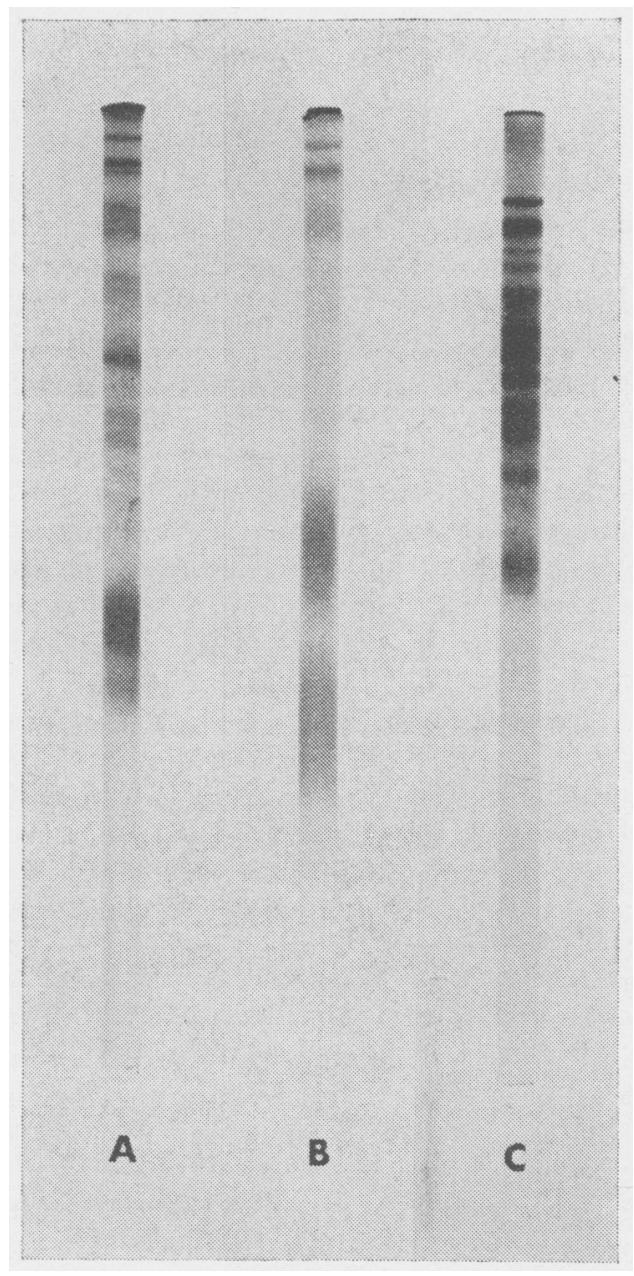

Text-fig. 1. Polyacrylamide gel electrophoresis (PAGE) of plasma membrane proteins from porcine spermatozoa. A, plasma membrane proteins solubilized with SDS-urea, separated by SDS-PAGE and stained with Coomassie Blue; B, same as (A) except stained with periodic acid-Schiff reagent; $C$, plasma membrane proteins solubilized with phenol-urea-acetic acid, separated with acidic PAGE and stained with Coomassie Blue.

With SDS-PAGE of plasma membrane proteins from porcine spermatozoa, 11 prominent bands were detected with estimated molecular weights ranging from 14,500 to 260,000 (Table 1; Text-fig. 1). In subsequent trials, improved resolution was achieved by reducing the amount of protein applied to the gels, and the bands with mean estimated molecular weights of 66,000 and 100,000 separated into two and three bands, respectively. Of the 11 bands detected originally, at least 6 contained glycoprotein. Four of the six glycoprotein bands had relatively high molecular weights $(140,000$ to 260,000$)$, while the other 2 were low in molecular weight $(14,500$ and 22,500$)$.

A substantial amount of PAS-positive protein remained at the origin of gels in SDS-PAGE. With $8 \%$ acrylamide gels, some high molecular weight proteins should not be able to enter the polyacrylamide matrix. Therefore, the plasma membrane of porcine spermatozoa probably contains proteins, including glycoproteins, having molecular weights above 260,000 . Other work in this laboratory (unpublished), using gel filtration on Sephadex G-200, supports that concept. 
When electrophoresis was conducted under acidic conditions so that the proteins from the plasma membrane migrated toward the cathode, 13 protein bands could be distinguished (Text-fig. 1). No attempt was made to relate individual bands in acidic PAGE to those observed in SDSPAGE.

Both methods of PAGE tended to separate the membrane proteins according to molecular weight. In the acidic gels, however, there was a tendency for migration rates to depend on sample volume. Also, not all of the protein entered the gels. That effect was probably due to exclusion of high molecular weight proteins by the $7 \cdot 5 \%$ acrylamide polymer (in a manner similar to SDS-PAGE). It is also possible that some of the protein aggregated at the origin in the acidic system because of the absence of phenol in the gels. The SDS-PAGE gels were therefore more suitable for molecular weight determinations (Zahler, 1975), although separation of the membrane proteins was more distinct with the acidic system. The improved resolution with the acidic system may be due to more effective dissociation of lipids from proteins by phenol (Steck \& Fox, 1972).

The presence of relatively large amounts of carbohydrate in glycoproteins can reduce the staining of the protein with Coomassie Blue (Glossmann \& Neville, 1971). It is therefore possible for a glycoprotein band in an electrophoresis gel to be PAS-positive, but fail to stain or stain very lightly with Coomassie Blue. Under these conditions, use of densitometry with Coomassie Blue for quantification of proteins in gels would be unreliable.

In addition to an effect on staining properties, the carbohydrate moiety of glycoproteins can alter the relationship between molecular weight and relative mobility by masking binding sites for SDS on the protein molecules (Segrest, Jackson, Andrews \& Marchesi, 1971). The result is usually a slower migration rate of the glycoprotein during SDS-PAGE, causing the molecular weights calculated for such a protein to be too high. Therefore, the molecular weight estimations for the glycoproteins in sperm plasma membrane are probably larger than the actual values.

It is likely that the protein profiles observed in these experiments represent only those proteins that are intrinsic components of the plasma membrane or are bound tightly to its surface. During the procedure for isolation of the membrane, spermatozoa were exposed to a relatively high concentration of EDTA and to a $\mathrm{pH}$ of approximately 5.5 . Those conditions, which were necessary to prevent agglutination, could remove loosely-bound proteins from the surface of the spermatozoon. Further experiments must be conducted to determine the extent of such loss from the plasma membrane and the nature of the proteins removed.

In the plasma membrane of spermatozoa, the carbohydrate moieties of the high molecular weight glycoproteins are probably located on the exterior surface of the cell. This hypothesis is supported by research which demonstrated that plant lectins bound to the plasma membrane of spermatozoa (Nicolson, Lacorbiere \& Yanagimachi, 1972; Nicolson \& Yanagimachi, 1972; Gordon, Dandekar \& Bartoszewicz, 1974) and provides an explanation for the net negative charge of spermatozoa (Cooper \& Bedford, 1971). In addition, alteration of the carbohydrate groups of the surface glycoproteins may be important in capacitation. Gordon et al. (1974) demonstrated that binding of concanavalin A was reduced after capacitation, and Vaidya, Glass, Dandekar \& Johnson (1971) have shown that the electrophoretic mobility of spermatozoa incubated in the uterus of oestrous females was significantly less than that of intact, ejaculated spermatozoa.

This investigation was supported by NIH Research Grant HD 07013. The cooperation of $\mathrm{Mr}$ F. H. Azzazi in providing access to unpublished results is appreciated. Journal Paper No. 6077 of the Purdue University Agricultural Experiment Station.

\section{References}

Aonuma, S., Mayumi, T., Suzuki, L., Noguchi, T., IWAI, M. \& OKabE, M. (1973) Studies on sperm capacitation. I. The relationship between a guineapig sperm-coating antigen and a sperm capacitation phenomenon. J. Reprod. Fert. 35, 425-432.

COOPER, G.W. \& BedFord, J.M. (1971) Acquisition of surface charge by the plasma membrane of mam- malian spermatozoa during epididymal maturation. Anat. Rec. 169, 300-301, Abstr.

Fairbanks, G., Steck, T.L. \& Wallach, D.F.H. (1971) Electrophoretic analysis of the major polypeptides of the human erythrocyte membrane. Biochemistry, N.Y. 10, 2606-2617.

Glossmann, H. \& Neville, D.M., JR (1971) Glyco- 
proteins of cell surfaces. Comparative study of three different cell surfaces of the rat. J. biol. Chem. 246, 6339-6346.

Gordon, M., Dandekar, P.V. \& Bartoszewicz, W. (1974) Ultrastructural localization of surface receptors for concanavalin A on rabbit spermatozoa. J. Reprod. Fert. 36, 211-214.

Johnson, W.L. \& Hunter, A.G. (1972) Seminal antigens: their alteration in the genital tract of female rabbits and during partial in vitro capacitation with beta amylase and beta glucuronidase. Biol. Reprod. 7, 332-340.

Lembi, C.A., Morré, D.J., St-Thomson, K. \& Hertel, R. (1971) N-1-Napthylphthalamic-acid-binding activity of a plasma membrane-rich fraction from maize coleoptiles. Planta $99,37-45$.

Lowry, O.H., Rosebrough, N.J., Farr, A.L. \& RANDALL, R.J. (1951) Protein measurement with the Folin phenol reagent. $J$. biol. Chem. 193, 265275.

Lunstra, D.D., Clegg, E.D. \& Morré, D.J. (1974) Isolation of plasma membrane from porcine spermatozoa. Prep. Biochem. 4, 341-352.

Morre, D.J., ClegG, E.D., Lunstra, D.D. \& MollenHAUER, H.H. (1974) An electron-dense stain for isolated fragments of plasma and acrosome membranes from porcine sperm. Proc. Soc. exp. Biol. Med. 145, 1-6.

Nicolson, G.L. \& Yanagimachi, R. (1972) Terminal saccharides on sperm plasma membranes: identification by specific agglutinins. Science, N.Y. 177, 276-279.

Nicolson, G.L., LACorbiere, M. \& Yanagimachi, R. (1972) Quantitative determination of plant agglutinin membrane sites on mammalian spermatozoa. Proc. Soc. exp. Biol. Med. 141, 661-663.
Oliphant, G. \& Brackett, B.G. (1973) Immunological assessment of surface changes of rabbit sperm undergoing capacitation. Biol. Reprod. 9, 404-414.

Penn, A., Gledhill, B.L. \& Darżynkiewicz, Z. (1972) Modification of the gelatin substrate procedure for demonstration of acrosomal proteolytic activity. J. Histochem. Cytochem. 20, 499-506.

Polakoski, K.L., McRorie, R.A. \& Williams, W.L. (1973) Boar acrosin. I. Purification and preliminary characterization of a proteinase from boar sperm acrosomes. J. biol. Chem. 248, 8178-8182.

Segrest, J.P., JaCkson, R.L., ANDrews, E.P. \& MARCHESI, V.T. (1971) Human erythrocyte membrane glycoprotein: a re-evaluation of the molecular weight as determined by SDS polyacrylamide gel electrophoresis. Biochem. Biophys. Res. Commun. 44, 390-395.

SNider, D.R. \& Clegg, E.D. (1975) Alteration of phospholipids in porcine spermatozoa during in vivo uterus and oviduct incubation. J. Anim. Sci. 40, 269-274.

STECK, T.L. \& Fox, C.F. (1972) Membrane proteins. In Membrane Molecular Biology, pp. 27-75. Eds C. F. Fox \& A. D. Keith. Sinavar Associates, Stanford, Connecticut.

Vaidya, R. A., Glass, R. H., Dandekar, P. \& Johnson, K. (1971) Decrease in the electrophoretic mobility of rabbit spermatozoa following intra-uterine incubation. J. Reprod. Fert. 24, 299-301.

Weber, K. \& OsBorN, M. (1969) The reliability of molecular weight determinations by dodecyl sulfatepolyacrylamide gel electrophoresis. J. biol. Chem. 244, 4406-4412.

ZAHLER, W.L. (1975) Analytical polyacrylamide gel electrophoresis and molecular weight determination. Meth. Enzymol. 32, 70-81.

Received 1 November 1975 